\title{
FLUX FOR ELECTRIC ARC SURFACING PROVIDING HIGH-TEMPERATURE REMOVAL OF SLAG COATING
}

\author{
N.M. STRELENKO ${ }^{1}$, L.A. ZHDANOV ${ }^{1}$ and I.A. GONCHAROV ${ }^{2}$ \\ ${ }^{1}$ NTUU «Kiev Polytechnic Institute» \\ 37 Pobeda Ave., 03056, Kiev, Ukraine. E-mail:strelenkon@gmail.com \\ ${ }^{2}$ E.O. Paton Electric Welding Institute, NASU \\ 11 Bozhenko Str., 03680, Kiev, Ukraine. E-mail: office@paton.kiev.ua
}

\begin{abstract}
It was shown as a result of analysis of mechanisms of slag crust removal from the weld metal surface that the spinels at slag-metal interface and their intergrowth have the main influence on this process. It was found on the basis of analysis of structure of spinels and slag melt that to prevent the formation of spinels at the interface and intergrowth of metal and slag, it is necessary to provide the presence in the slag melt of a structural element with configuration of a linked structure, differed from tetra- and octahedral structures, and not capable to formation of spinels. It was established that prevention of formation of spinels in providing necessary welding-technological properties of flux of $\mathrm{SiO}_{2}-\mathrm{Al}_{2} \mathrm{O}_{3}-\mathrm{MgO}-\mathrm{CaF}_{2}$ system can be attained at adding of zirconium oxide in the amount of 3.5-5.5\% into flux composition. The flux has been developed, which provides a spontaneous removal of slag coating at high temperatures. 13 Ref., 6 Figures.
\end{abstract}

$\boldsymbol{K} \boldsymbol{e} \boldsymbol{y} \boldsymbol{w} \boldsymbol{O} \boldsymbol{r} \boldsymbol{d} \boldsymbol{s}:$ submerged arc surfacing, high-temperature removal of slag coating, metal-slag interface, complex compounds of oxides, spinels, zirconium oxide, slag systems

The process of submerged arc surfacing is one of the widely spread methods of restoration of parts of metallurgical, mining, machine-building equipment, agricultural machines and automobile transport. Using surfacing it is possible to deposit a layer of almost any thickness, different chemical composition and physical-mechanical properties by applying optimum combination of wire-flux filler materials. In restoration of parts the general-purpose fluxes AN-348A, OSTs-45, $\mathrm{AN}-60, \mathrm{AN}-47$ and specialized fluxes AN-20, AN-28, $\mathrm{AN}-26, \mathrm{AN}-44$ found the widest application. The submerged arc surfacing is used in restoration of parts, having flat and cylindrical surfaces, including also surfaces of intricate configuration, with a sufficient wear usually (up to $3-5 \mathrm{~mm}$ ). In this case the surfacing is usually made with a partial or complete overlapping of the deposited layer.

Coming from specifics of used materials, the technology of surfacing should be realized in a multi-pass, continuous condition, and with preheating in some cases. This stipulates the strict requirements for removal of slag coating from the deposited bead surface within the range of elevated temperatures. The fluxes, produced by industry now, do not meet this requirement.

Therefore, the aim of the present work was the evaluation of factors and detailed study of mechanism, defining and providing the process of high-temperature removal of slag, formation

(C) N.M. STRELENKO, L.A. ZHDANOV and I.A. GONCHAROV, 2014 of slag system, and optimization of the flux composition.

Removal of slag coating from the weld metal surface can be provided by [1-3]:

- increase in difference of coefficients of thermal expansion (CTE), which generate shearing forces during welded joint cooling;

- decrease in oxidizing ability of slag in molten state at its crystallization;

- delay of processes chemisorption at the slagmetal interface by increasing the surface and interfacial tension, which retards the process of intergrowth of metal and slag.

The oxidizing ability of slag in crystallization and processes of chemisorption cause the formation of chemical compounds of spinel type, which can strongly retain the slag coating on the weld metal surface. Even in case of a significant difference in coefficients of linear expansion at spontaneous removal of slag crust the thin glassy layers of solid flux, strongly bound with metal, remain on the metal. Their removal requires additional forces because they will interfere the further technological operations.

Effect of CTE on high-temperature removal of slag is not adequate in general case. In work [4] the thermogram of dilatometry of welding slags in the process of heating and cooling is presented. The processing of data for flux AN348A, carried out by us, showed that during heating of slag crust after $870{ }^{\circ} \mathrm{C}$ temperature the decrease in value of CTE is observed, which even becomes negative. This is, probably, due to break of chemical bonds in structural constituents of a chain silicate, which is accompanied by their decomposition for simpler mineral compounds. As 
$\alpha_{\mathrm{Mc}} \cdot 10^{-7}, \alpha_{\mathrm{sl}}{ }^{1} 10^{-6}$

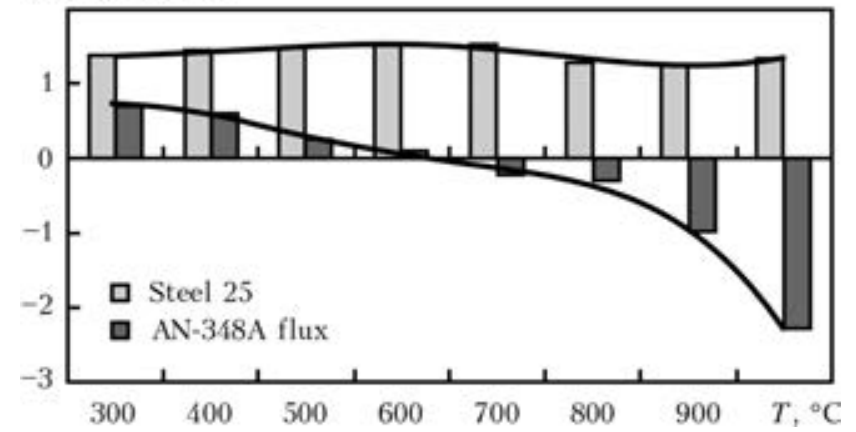

Figure 1. CTE change in cooling of slag $\left(\alpha_{\mathrm{Sl}}\right)[5]$ and metal $\left(\alpha_{\mathrm{Me}}\right)[6]$

a result, the structure of material is ordered and simplified with a system transition into the more stable state, which is typical of formation of a pyroxene structure. It is clear that the main interest is the change of CTE during the slag cooling. Data in Figure 1 show that unlike the metal, where CTE has the same sign of expansion value with increase in temperature at some maximum in the range of $500-700{ }^{\circ} \mathrm{C}$, CTE for fluxes is characterized by the change in sign. During cooling the slag is elongated and, as result, in the range of $600-700{ }^{\circ} \mathrm{C}$ the values of CTE are in the region of zero. After that the CTE of slag begins to increase and reaches its maximum after $200{ }^{\circ} \mathrm{C}$. The given data show that it is the hightemperature region, where the maximum difference in CTE is observed, and with decrease in temperature the difference in CTE of metal and slag is decreased. At the same time the removal of slag crust for flux AN-348A is observed only after the slag cooling. It should be noted that values CTE for metal and slag are differed almost by one order. The given data allow us to conclude that the difference in CTE of metal and slag does have a determinative influence on the processes

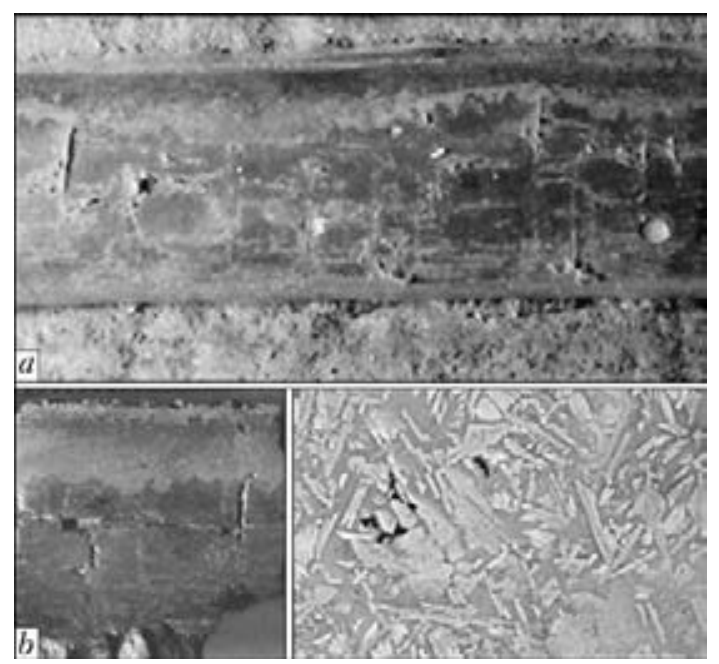

Figure 2. Surface of weld metal and slag crust in arc surfacing under flux DFK-2: $a-$ macrospinels at the weld metal surface $(\times 2) ; b-$ macro- and microimaging of slag crust $(\times 1500)$ of slag coating removal in the range of high temperatures.

Other factors, influencing the process of slag removal, include also its oxidizing ability at slagmetal interface in the conditions, when slag is in solid or solid-molten state and forms the weld. In this case the intensive processes of chemisorption at slag-metal boundary with formation of complex compounds, retaining the slag on the metal surface, can proceed. Problems, connected with the formation of spinels, initiator of which is the weld metal, and final building of lattice of oxidized surface, have been studied comprehensively enough [2-4]. Data on effect of complexing elements in the flux composition and its oxidizing ability on the processes of formation of spinels are insufficient in literature.

To study this problem, we have manufactured special «short fluxes» on the base of slag system $\mathrm{TiO}_{2}-\mathrm{MgO}-\mathrm{MnO}-\mathrm{SiO}_{2}-\mathrm{Al}_{2} \mathrm{O}_{3}$ with increased content of oxides of titanium and magnesium: 40 and $30 \% \mathrm{TiO}_{2}, 17$ and $32 \% \mathrm{MgO}$. Fluxes DFK-2 and DFK-3 are high-titanium, «short» and have ultra-narrow interval of crystallization. Melting temperature of flux DFK-2 is $1380{ }^{\circ} \mathrm{C}$ at viscosity of $0.45 \mathrm{~Pa} \cdot \mathrm{s}$, and in DFK-3 flux the temperature interval of crystallization at viscosity of $0.9-$ $0.5 \mathrm{~Pa} \cdot \mathrm{s}$ is $1400-1500{ }^{\circ} \mathrm{C}$. Selection of high-titanium fluxes for clarification of problem about effect of flux composition on complexing at slagmetal boundary was predetermined by the fact that titanium itself is the element, on the base of which the spinels can be built, and change in concentration of magnesium oxide should regulate the flux oxidizing ability.

Results of investigation of surface of weld metal and slag crust show the presence of macroformations on the weld metal surface, the prints of which are available on slag crust (Figure 2). Local chemical analysis of slag crust showed that these formations are macrospinels, which are formed on the base of titanium microspinels (53$69 \%$ ) and manganese (20-23\%) [7].

Taking into account the high crystallization capability of titanium-containing slags, the presence of macrospinels on the surface of weld metal for flux with increased content of titanium oxide (flux DFK-2), their association with the process of formation of microspinels on the slag surface, and also changed character of slag bonding with metal at increase of magnesium oxide in flux composition (flux DFK-3; Figure 3), it can be assumed that adding into the flux composition of elements, which reduce the oxidizing ability of slag surface during its crystallization and after the slag solidification, should decrease abruptly the possibility of formation of spinel-like formations at slag-metal interface and prevent the in- 
tergrowth of slag coating with the oxidized surface of weld metal.

Spinels are characterized by common structure formulae: $\mathrm{Me}^{2+}\left[\mathrm{Me}^{3+}\right] \mathrm{O}_{4}$ and $\mathrm{Me}^{3+}\left[\mathrm{Me}^{2+} \mathrm{Me}^{3+}\right] \mathrm{O}_{4}$, where $\mathrm{Me}^{2+}$ is the $\mathrm{Mg}^{2+}, \mathrm{Zn}^{2+}, \mathrm{Mn}^{2+}, \mathrm{Fe}^{2+}, \mathrm{Ni}^{2+}$, $\mathrm{Co}^{2+} ; \mathrm{Me}^{3+}$ is the $\mathrm{Al}^{3+}, \mathrm{Mn}^{3+}, \mathrm{Fe}^{3+}, \mathrm{V}^{3+}, \mathrm{Cr}^{3+}$, $\mathrm{Ti}^{4+} ;[$ ] are the ions in octahedral voids. Spinels are crystallized in cubic system, forming mainly the octahedral crystals. In elementary cell of spinel structure 32 oxygen anions form the most dense cubic packing with 64 tetrahedral voids ( 8 is occupied by cations) and 32 octahedral voids (16 is occupied by cations).

Slag melts in accordance with polymeric theory of constitution of slags $[8,9]$ represent the dense packed ion melts, where oxygen ions are observed in two types of voids, namely tetrahedral and octahedral. Tetrahedral voids are occupied by cations $\mathrm{Si}^{4+}, \mathrm{Ti}^{4+}$ and partially by $\mathrm{Al}^{3+}$, $\mathrm{Fe}^{3+}$. These elements are located in quaternary coordination by oxygen and are the complexing agents. Octahedral voids are occupied by cations $\mathrm{Ca}^{2+}, \mathrm{Mg}^{2+}, \mathrm{Fe}^{2+}$ and partially by $\mathrm{Al}^{3+}, \mathrm{Fe}^{3+}$, $\mathrm{Ti}^{3+}, \mathrm{Ti}^{4+}, \mathrm{Ti}^{6+}$. These elements are located in sixdimensional coordination and do not form complexes. It is evident that the presence of cations of a common sign in slag and metal leads to the appearance of spinels.

To prevent the formation of spinels between metal and slag and eliminate their intergrowth, it is necessary to have the element in slag melt, which does not form spinels, has an increased affinity to oxygen at temperatures typical of the process of crystallization of slag melt, forms strong chemical compounds, and the configuration of linked structure in complexes is differed from tetraand octahedral ones. One of these elements is zirconium oxide, which at the condition of realization of maximum coordination number by oxygen (eight), forms the high-temperature cubic modification [10]. This modification is retained in interaction with cations, having the degree of oxidation, which differs from cation $\mathrm{Zr}^{4+}$, i.e. from all the spinel-forming elements.

Change in phase composition of zirconium dioxide is started from temperature of $900{ }^{\circ} \mathrm{C}$, at which the decrease in fraction of monoclinic phase is observed, at $1050{ }^{\circ} \mathrm{C}$ the phase monoclinic-tetragonal transition is occurred, and already at $1100{ }^{\circ} \mathrm{C}$ the phase composition is completely defined by meta-stable tetragonal $\mathrm{ZrO}_{2}$. From $2300{ }^{\circ} \mathrm{C}$ up to melting point of $2715{ }^{\circ} \mathrm{C}$ it is transferred into non-stable cubic modification. Oxides $\mathrm{CaO}$ and $\mathrm{MgO}$ provide stabilizing properties to modification $\mathrm{ZrO}_{2}$, which partially loss this property in the presence of $\mathrm{Al}_{2} \mathrm{O}_{3}$ [11]. Adding of zirconium oxide into slag melt changes not only its oxidizing ability, but also the physical properties. Here, on the one hand, it is necessary to prevent the formation of refractory slags, that

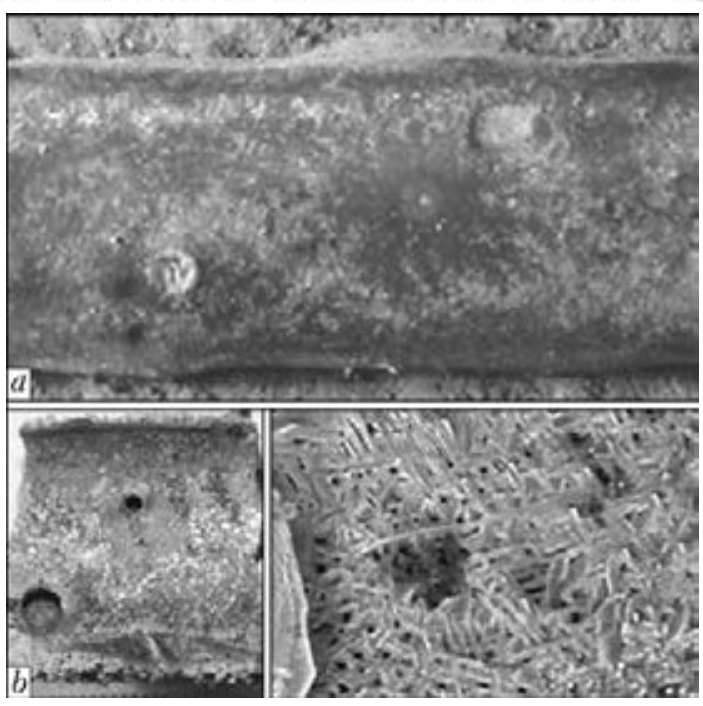

Figure 3. Surface of weld metal and slag crust in arc surfacing under flux DFK-3: $a-$ traces of intergrowth of weld metal and slag surfaces $(\times 2) ; b-$ macro- and microimaging of slag crust $(\times 1500)$

is connected with the possibility of zirconium oxide to be built-in into silicate, polymeric matrix and, by distributing uniformly in it, to modify it ( size of $\mathrm{ZrO}_{2}$ crystallites is $7-19 \mathrm{~nm}$ ) [12], and, on the other hand, it is necessary to provide the reduction in oxidizing potential at the slagmetal interface.

To realize the offered mechanism of control of spinel formation and to develop the flux for electric arc surfacing, which will provide the high-temperature removal of slag coating, we have selected the traditional system $\mathrm{SiO}_{2}-$ $\mathrm{Al}_{2} \mathrm{O}_{3}-\mathrm{MgO}-\mathrm{CaF}_{2}$, for which the following concentrations of components were established: 20, 28,18 and $14 \%$ with additions of $4 \% \mathrm{TiO}_{2}$ and $\mathrm{MnO}$. Seven experimental agglomerated fluxes with changeable content of $\mathrm{ZrO}_{2}$ from 0 to $15 \%$ were manufactured, which were marked as DFZr; DFZr-1.5; DFZr-2.5; DFZr-3.5; DFZr-5.5; DFZr-10 and DFZr-15. Ratio of concentrations of components in fluxes was corrected by main components.

Using fluxes of series DFZr, the multilayer surfacing was performed on specimens of steel VSt3sp (killed) by $4 \mathrm{~mm}$ diameter wire $\mathrm{Sv}^{-}$ 08G1NMA. When it was possible, the surfacing was made in a continuous mode with record of temperature of slag removal by infrared, no-contact thermometer of Fione 506ip type. Slag removal was evaluated by 5 -point scale using differential method [13].

As a result, spontaneous removal of slag coating for fluxes DFZr-3.5 and DFZr-5.5 in the fifth layer at $600-700{ }^{\circ} \mathrm{C}$ was established. Using fluxes DFZr, DFZr-10 and DFZr-15, the continuous process of surfacing was not successful. To apply flux DFZr, the large mechanical force is required to remove the slag crust, fluxes DFZr-10 and DFZr-15 did not provide the quality formation 


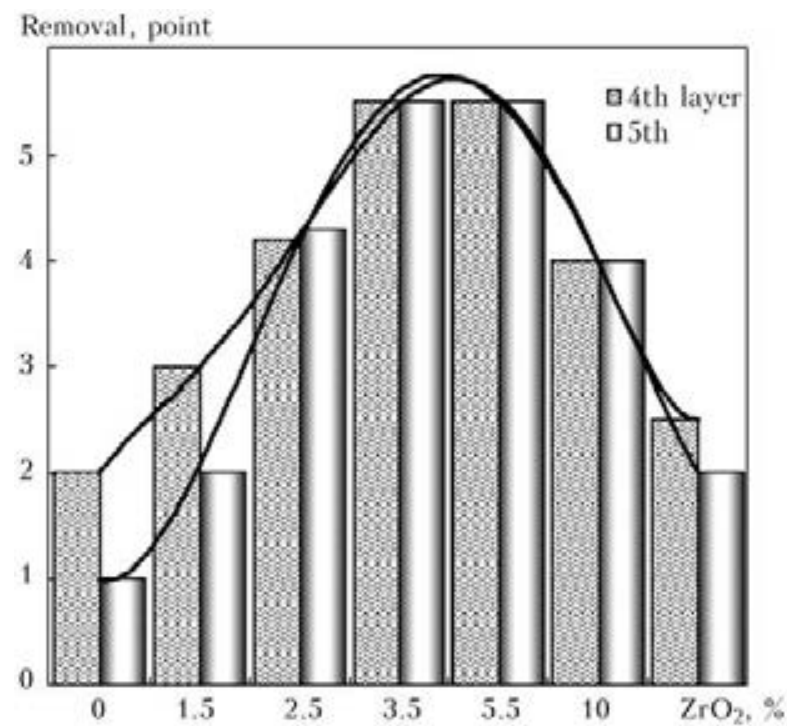

Figure 4. Relationship of removal of slag coating of series DFZr fluxes in the fourth and fifth layers

of weld metal and, as a consequence, slag was sticking, and additional mechanical actions were required. Generalized results on slag crust removal are presented in Figure 4. Temperature relationships of viscosity of welding fluxes of series DFZr obtained by a rotary method ( Figure 5) allow explaining the deterioration of weld formation at increase of zirconium oxide in flux composition by significant increase in slag refractoriness. For fluxes, containing 2.5$5.5 \% \mathrm{Zr}$, polytherms of viscosity are in the one range of values. The rate of viscosity growth for these fluxes is somewhat higher than for flux DFZr, that has a positive effect on their forming capacities. It is worthy to note that fluxes DFZr2.Zr and DFZr-3.5 have viscosity of 0.13 and $0.16 \mathrm{~Pa} \cdot \mathrm{s}$ at $1460{ }^{\circ} \mathrm{C}$, and DFZr-5.5 - 0.06 Pa.s. This proves the non-adequate effect of zirconium oxide of structure formations in slag melt.

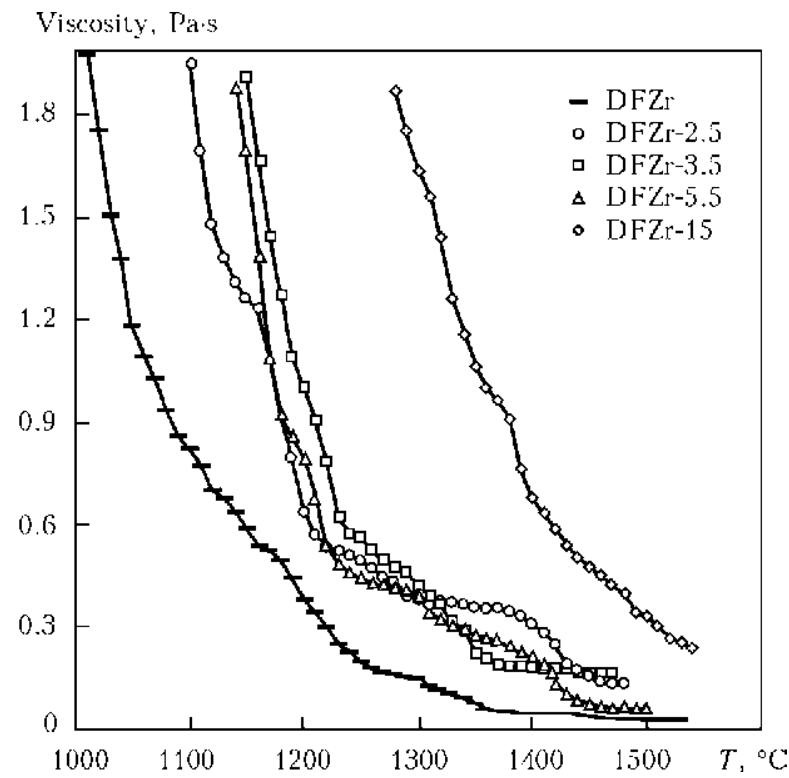

Figure 5. Viscosity of series DFZr fluxes versus temperature
Local chemical analysis of slag crust showed that its base (points 3 and 4; Figure 6,a) are the polymers of composition, wt.\%: $24-27 \mathrm{SiO}_{2}$, 17-19 $\mathrm{TiO}_{2}, 20-25 \mathrm{CaO}, 9-11 \mathrm{Al}_{2} \mathrm{O}_{3}$ with addition of 11-13 $\mathrm{MnO}$ and 3-4 MgO. The observed formations (points 1 and 2; Figure 6, $a$ ) are spinels on base of iron oxide, wt.\%: 67-69 FeO with 6-14 $\mathrm{MnO}$, 4-8 $\mathrm{TiO}_{2}$, 4-12 $\mathrm{CaO}$, 1$7 \mathrm{MgO}, 8-31 \mathrm{Al}_{2} \mathrm{O}_{3}, 5-7 \mathrm{SiO}_{2}$. The given composition of local formations and base of slag crust show that spinels are formed between the slag and metal. Moreover, the slag crust base is nonuniform (see Figure $6, a$ ), and the surface layer is enriched with $\mathrm{TiO}_{2}, \mathrm{CaO}$ and $\mathrm{MnO}$, that proves also about the processes of slag and metal intergrowth. It is these factors that are the cause of a poor removal (see Figure 4).

Addition of $\mathrm{ZrO}_{2}$ to the flux changes the slag crust structure (Figure 6, b, c). At $3.5 \% \mathrm{ZrO}_{2}$ content the clearly expressed separate formations of white color are observed on the slag surface,
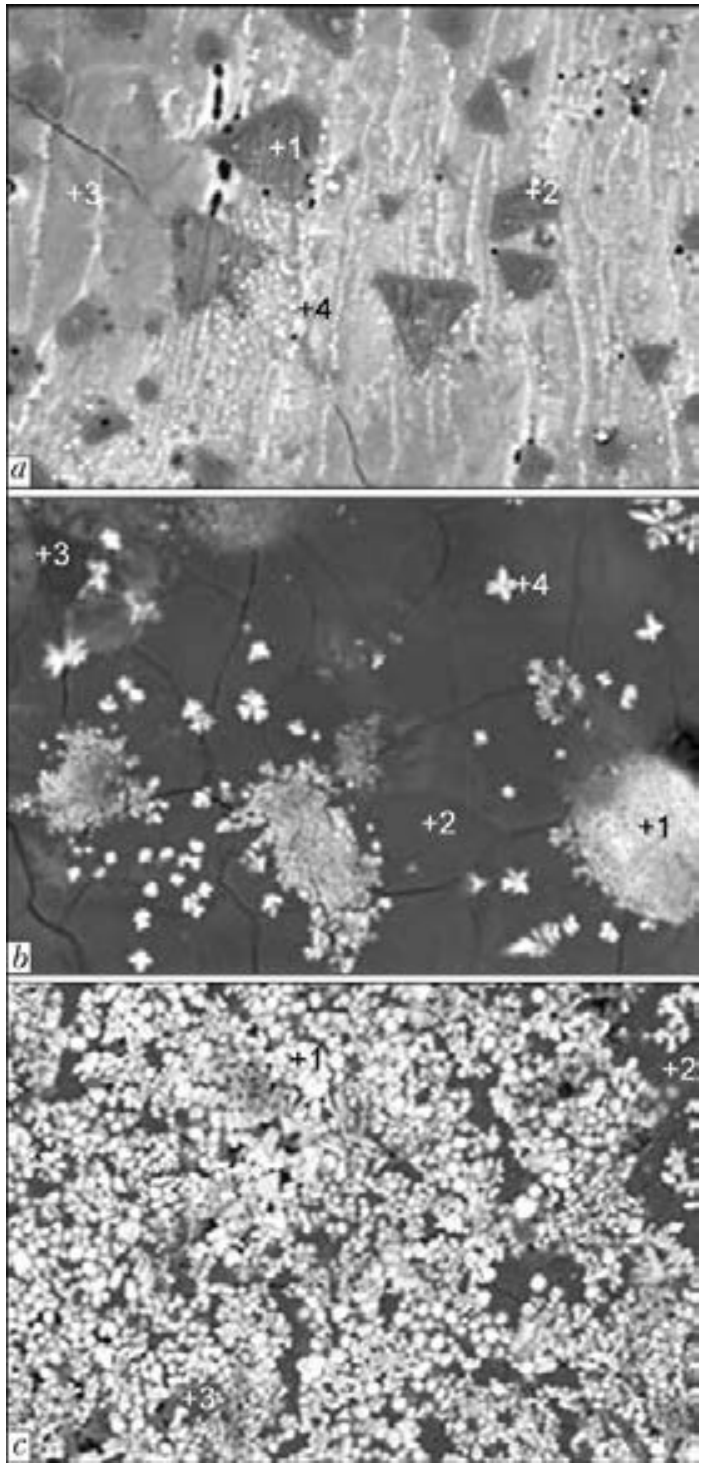

Figure 6. SEM-microstructure $(\times 1550)$ of slag crust surface: $a$ - flux DFZr; $b-$ DFZr-3.5; $c-$ DFZr-15 
which are the compounds on zirconium oxide base (chemical composition in points 1 and 4 is, wt.\%: 57-67 $\mathrm{ZrO}_{2}, 6-10 \mathrm{SiO}_{2}, 8-13 \mathrm{CaO}, 5 \mathrm{TiO}_{2}, 5-$ $7 \mathrm{MnO}, 3-4 \mathrm{Al}_{2} \mathrm{O}_{3}$ ) (see Figure 6, b). The slag crust base (points 2 and 3 ) represents a monolithic, smooth structure with microcracks (wt.\%: 19-21 $\mathrm{SiO}_{2}, \quad 7-12 \mathrm{TiO}_{2}, \quad 25-49 \mathrm{CaO}, 4-$ $10 \mathrm{Al}_{2} \mathrm{O}_{3}, 13-30 \mathrm{MnO}, 4-8 \mathrm{ZrO}_{2}$ ). Coming from composition of formations, available on the slag crust surface, and appearance on microimaging of base of slag surface, it is seen that spinels and intergrowth of slag crust with weld metal is not observed. As a result, spontaneous removal of crust, including that at elevated temperatures, is provided (see Figure 4). The presence of zirconium oxide in the composition of flux base proves the partial built-in of zirconium cation $\mathrm{Zr}^{4+}$ into polymeric lattice of silicon anions, resulting in transfer of viscosity polytherm into the region of the higher temperatures.

Structure of surface of slag with increased content of zirconium oxide (DFZr-15) consists completely of formations of zirconium compound, which are arranged on the slag surface adjacent to weld metal. Composition of zirconium compounds is close to earlier described structures, wt.\%: 62-72 $\mathrm{ZrO}_{2}, 6-10 \mathrm{SiO}_{2}, 7-$ $11 \mathrm{CaO}, 3 \mathrm{TiO}_{2}, 6-7 \mathrm{MnO}, 3-4 \mathrm{Al}_{2} \mathrm{O}_{3}$ (point 1; see Figure $6, c)$. Composition of base (points 2 and 3 ) is also close to base of flux DFZr3.5, wt.\%: 20-23 $\mathrm{SiO}_{2}, 9-10 \mathrm{TiO}_{2}, 19-24 \mathrm{CaO}, 10-$ $11 \mathrm{Al}_{2} \mathrm{O}_{3}, 7-8 \mathrm{MnO}, 13-26 \mathrm{ZrO}_{2}$. The increased content of zirconium oxide in slag base, i.e. its building-in into polymeric ion frame, leads to increase in melting temperature of flux, the slag becomes more refractory, that influences negatively on its forming capabilities in welding. Weld surface becomes non-uniform, influencing negatively on the processes of slag removal.

As a result, experimental fluxes DFZr-3.5 and DFZr-5.5 can be recommended as a basic composition of flux for surfacing works providing the high-temperature removal of the slag coating. Technical Specifications were worked out and registered for this flux (TS U 24.6-05416923101:2011, welding flux of ANK-73 grade).

\section{Conclusions}

1. On the basis of analysis of literature data the possible causes and mechanism of high-temperature removal of slag crust from the weld metal surface were defined. It was shown that during the process of slag cooling the difference in CTE is observed in high-temperature region proper, and at the temperature decrease the difference in CTE of metal and slag is decreased.

2. It was found that spontaneous removal of slag coating in the region of high temperatures can be provided only by prevention of spinel for- mations at slag-metal interface and absence of slag intergrowth with weld metal surface.

3. It was shown on the basis of analysis of structure of spinels and slag melt, from the point of view of polymeric theory of slag constitution, that to prevent the formation of spinels at the interface, development of processes of metal and slag intergrowth, it is necessary to provide the presence of structure element in slag melt, having an increased affinity to oxygen not capable to formation of spinels, and configuration of linked structure of which was different from tetra- and octahedral ones.

4. It is shown that it rational to add the zirconium oxide into composition of fluxes for providing the high-temperature removal of slag crust. The study of microstructure and local chemical analysis of slag crusts of fluxes of $\mathrm{SiO}_{2}-$ $\mathrm{Al}_{2} \mathrm{O}_{3}-\mathrm{MgO}-\mathrm{CaF}_{2}$ system with different concentration of $\mathrm{ZrO}_{2}$ showed that its adding into flux composition in the amount of 3.5-5.5\% prevents the formation of spinels and intergrowth of slag crust with weld metal. Flux has been offered for electric arc surfacing, guaranteeing the high-temperature (up to $600^{\circ} \mathrm{C}$ ) removal of the slag coating.

1. Zhdanov, L.A., Strelenko, N.M., Zvorykin, K.O. et al. (2010) Physical-chemical peculiarities of slag crust removal from weld metal surface and procedural base of evaluation methods. Tekhnolog. Sistemy, 1, 109-115.

2. Pokhodnya, I.K., Yavdoshchin, I.R., Karmanov, V.I. et al. (1974) Mechanism of adhesion of slag crust with weld surface. Avtomatich. Svarka, 5, 5-9.

3. Moravetsky, S.I. (2011) Detachability of slag crust in arc welding (Review). Pt 1: Mechanism of chemical adhesion of slag crust to weld metal. The Paton Welding J., 1, 28-31.

4. Moravetsky, S.I. (2011) Detachability of slag crust in arc welding (Review). Pt 2: Character of the effect of main factors on detachability of slag crust. Ibid., 2, 20-23.

5. Ignatov, M.N., Ignatova, A.M., Naumov, S.V. et al. (2012) Study of relationship between thermal expansion coefficients of weld metal and welding slags and temperature in range of $100-1000{ }^{\circ} \mathrm{C}$. Obrabotka Metallov, 56(3), 116-119.

6. Zubchenko A.S., Koloskov, M.M., Kashirsky, Yu.V. et al. (2003) Handbook of steel and alloy grades. Moscow: Mashinostroenie.

7. Strelenko, N.M., Zhdanov, L.A. (2012) Specifics of formation of spinels on slag-metal interface in submerged-arc welding. Visnyk Donbas. Mashynobud. Akademii, 28(3), 260-263.

8. Novikov, V.K. (1987) Development of polymer model of silicate melts. Rasplavy, 6(1), 21-23.

9. Novikov, V.K., Nevidimov, V.N. (2006) Polymer nature of melted slags. Ekaterinburg: GOU VPO UG-TU-UPI.

10. Orgel, L. (1965) Introduction to chemistry of transition metals. Moscow: Mir.

11. Pashkeev, I.Yu. (2005) Interaction of $\mathrm{ZrO}_{2}$ in melts of system $\mathrm{Al}_{2} \mathrm{O}_{3}-\mathrm{ZrO}_{2}$ with additions of oxides of lanthanum subgroup. Vestnik YuUGU, 3, 92-95.

12. Poddenezhny, E.N., Bojko, A.A. (2003) Classification of methods for manufacturing of ultradispersed oxide powders (Review). Vestnik P.O. Sukhoj $G G T U, 1,21-28$.

13. $R D$ 03-613-03: Sequence of welding consumables application in production, mounting, repair and reconstruction of technical devices for dangerous manufacturing entity. Technological schedule of certification of welding consumables. Moscow: PIO OBTB.

Received 29.04.2014 